\title{
Arachidonate-dependent Oxygen Consumption in Dictyostelium discoideum
}

\author{
By DIANE C. KRILL AND CHRISTOPHER D. TOWN* \\ Biology Department, Case Western Reserve University, Cleveland, OH 44106, USA
}

(Received 9 February 1988; revised 15 April 1988)

A central feature of the processes of aggregation and differentiation in the cellular slime mould Dictyostelium discoideum is the periodic excitatory cycle. Originally thought to involve primarily fluctuations in cyclic AMP levels, this excitatory cycle has since been shown to involve changes in several other second messengers including cyclic GMP, calcium and inositol trisphosphate. Previous work from this laboratory using specific inhibitors strongly suggested a role for eicosanoids in this stimulus-response process. Production of eicosanoids from fatty acid precursors is an oxygen-consuming process. In this paper, we report on oxygen consumption measurements in intact $D$. discoideum cells and in cell extracts. We demonstrate the existence of an azide-insensitive component of oxygen consumption which can be stimulated by the addition of arachidonate and other polyunsaturated fatty acids, and at least partially inhibited by meclofenamate and eicosatetraynoic acid, both of which block eicosanoid biosynthesis in higher organisms. These observations provide further evidence for the existence of an eicosanoidmetabolizing system in $D$. discoideum.

\section{INTRODUCTION}

The removal of nutrients from undifferentiated Dictyostelium cells initiates a complex network of cell interactions which ultimately results in the formation of differentiated multicellular fruiting bodies consisting of stalk cells and spores. A central feature and driving force of the process of cell aggregation and differentiation is the cAMP excitatory cycle. In this process, the extracellular chemoattractant cAMP binds to and activates cell surface receptors and initiates a set of second messenger responses, which include ion fluxes $\left(\mathrm{H}^{+}, \mathrm{K}^{+}\right.$and $\left.\mathrm{Ca}^{2+}\right)$, changes in cGMP and cAMP levels (Loomis, 1982) and, as was recently shown, increases in inositol 1,4,5-trisphosphate levels (Newell et al., 1987). These messengers, singly or in combination, are presumed to be responsible for the various movement and differentiation responses displayed by the cells.

Another class of lipid-derived cellular messengers whose importance in mammalian systems is becoming increasingly apparent is the eicosanoids. These compounds, which are formed by the enzymic oxidation of arachidonic acid (AA), include the prostaglandins (PGs), leukotrienes and hydroxyeicosatetraenoic acids. We recently showed that a structurally diverse set of antiinflammatory compounds which, in higher animals, inhibit eicosanoid reactions, were all capable of inhibiting both developmental gene expression and terminal cell differentiation in Dictyostelium discoideum (Town et al., 1985). We also showed that some of the same group of inhibitors blocked both cAMP-induced cell excitation and cAMP-induced cAMP accumulation in developing cells (Sampson \& Town, 1985). These observations led us to suggest that eicosanoids were intimately involved in the production and maintenance of the periodic excitatory oscillations which underlie Dictyostelium development. Further support for this

Abbreviations: AA, arachidonic acid; ETYA, eicosatetraynoic acid; Mec, meclofenamate; PG, prostaglandin; PUFA, polyunsaturated fatty acid; SHAM, salicylhydroxamic acid. 
comes from the earlier observations of Chung \& Coe (1978) on the effect of exogenous $\mathrm{PGE}_{1}$ on excitatory responses in cell suspension, and the work of Dohrmann et al. (1984) showing that AA affects both chemotaxis and thermotaxis in migrating slugs.

In the present work, we provide further support for this idea by demonstrating the presence of an AA-dependent oxygenase reaction both in intact cells and cell-free extracts from $D$. discoideum.

\section{METHODS}

Culture conditions. Dictyostelium discoideum strain AX-3 was used for all experiments and was cultured axenically using the medium described by Watts \& Ashworth (1970). Development was initiated by removing the amoebae from the nutrient broth by centrifugation (1500 r.p.m.). The cell pellet was washed and the cells were resuspended in a non-nutrient phosphate buffer $\left(20 \mathrm{mM}-\mathrm{KPO}_{4}, 2 \mathrm{mM}-\mathrm{MgSO}_{4}, \mathrm{pH} 6.2\right)$ at $10^{7}$ cells ml${ }^{-1}$. Cell lysates were prepared by suspending AX-3 cells in ice-cold homogenization buffer $(20 \%, \mathrm{v} / \mathrm{v}$, glycerol, 0.1 M-tricine, $1 \%$, v/v, cemulsol, $35 \mathrm{~mm}-\mathrm{KCl}, 10 \mathrm{~mm}-\mathrm{NaCl}, 2 \mathrm{~mm}$-EGTA, $10 \mathrm{mM}$-magnesium acetate, $\mathrm{pH} 8.0$ ). To prepare post-mitochondrial supernatants, cell lysates were centrifuged at $10000 \mathrm{~g}$ and the supernatant was stored at $-70{ }^{\circ} \mathrm{C}$ at a protein concentration of $40 \mathrm{mg} \mathrm{m}^{-1}$. For most experiments this supernatant was diluted to $3.6 \mathrm{mg} \mathrm{ml}^{-1}$ in the oxygen chamber.

Oxygen electrode measurements. Oxygen uptake measurements were done with a Yellow Springs Instruments (model no. 53) Clark-type polarographic electrode in a temperature-controlled chamber at $30^{\circ} \mathrm{C}$. Oxygen uptake was plotted with a $100 \mathrm{mV}$ Hitachi chart recorder. Calibration of the electrode was achieved by setting $0 \%$ with sodium dithionite and $100 \%$ with air-saturated distilled water (Umbreit et al., 1972). Oxygen consumption was calculated from the slope of the tracing after allowing one minute for mixing, and is expressed in $\mu \mathrm{O}_{2} \mathrm{~min}^{-1}$ (mg protein $)^{-1}$.

Labelled $A A$ incubation and lipid extraction. Lysates from vegetative and developing cells were incubated with $318 \mu \mathrm{M}-\mathrm{AA}, 2 \mathrm{mM}-\mathrm{Ca}, 0.25 \mu \mathrm{Ci}$ uniformly-labelled [ $\left.{ }^{14} \mathrm{C}\right] \mathrm{AA}\left(390 \mathrm{mCi} \mathrm{mmol}{ }^{-1}: 14.43 \mathrm{GBq} \mathrm{mmol}^{-1}\right)$ and $6 \mathrm{mM}^{-}$ sodium azide in the presence and absence of $50 \mu \mathrm{M}$-eicosatetraynoic acid (ETYA). AA and ETYA were added from stock solutions in ethanol of $164 \mathrm{~mm}$ and $2 \mathrm{mM}$ respectively. The final ethanol concentration in these incubations was $1.8 \%(\mathrm{v} / \mathrm{v})$, which was shown to have no effect on the oxygen consumption or reaction products. After a $15 \mathrm{~min}$ incubation period at $30^{\circ} \mathrm{C}$ the samples were removed to an ice-bath and acidified with $2 \mathrm{M}$ formic acid ( $\mathrm{pH} 3.5$ ), then sonicated and extracted twice with ethyl acetate. The combined extracts were then evaporated under nitrogen and resuspended in ethanol.

HPLC. Extracts were applied to a reverse-phase $\mathrm{C}_{18}$ column (Waters) and eluted with a solvent of methanol/water $(67: 33, \mathrm{v} / \mathrm{v}), 0.02 \%$ acetic acid adjusted to $\mathrm{pH} 4.7$ with $1.7 \mathrm{M}$-ammonium hydroxide (Jakschik $e t$ $e l ., 1982$ ). An increasing gradient (Waters model 660, programme no. 7) of methanol was used to elute the less polar cell products and unconverted AA. The volume of extract loaded on the column was adjusted for recovery of the label. The individual fractions were collected and counted with a Beckman scintillation counter.

\section{RESULTS}

\section{Effect of indomethacin on oxygen consumption in intact cells}

Preliminary experiments were done to determine oxygen consumption in intact cells.

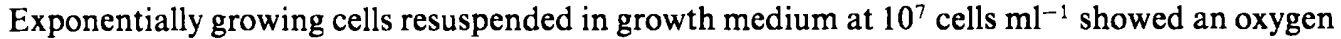
consumption rate of $3 \cdot 14 \mu 1 \mathrm{O}_{2} \mathrm{~min}^{-1}$ per $10^{7}$ cells. Increasing concentrations of sodium azide were then added to produce maximum inhibition of respiration. This was achieved at $6 \mathrm{~mm}-$ azide, which reduced oxygen consumption to $0.22 \mu 1 \mathrm{O}_{2} \mathrm{~min}^{-1}$ per $10^{7}$ cells. Developing cells were equally or more sensitive to azide inhibition.

To investigate the effects of indomethacin, cells of different developmental ages were placed in the measurement chamber, and oxygen consumption was measured in untreated cells and then after sequential additions of $6 \mathrm{~mm}$-sodium azide, followed by $500 \mu \mathrm{M}$-indomethacin. For cells of each developmental age, a substantial level of azide-resistant oxygen consumption remained after inhibition of respiration, and in each case this was partially inhibited by indomethacin. These results are shown in Fig. 1, and are summarized in Table 1 . The maximum effect of indomethacin was seen in cells starved for $3 \mathrm{~h}$ when $65 \%$ of the azide-insensitive oxygen consumption was inhibited by indomethacin. 


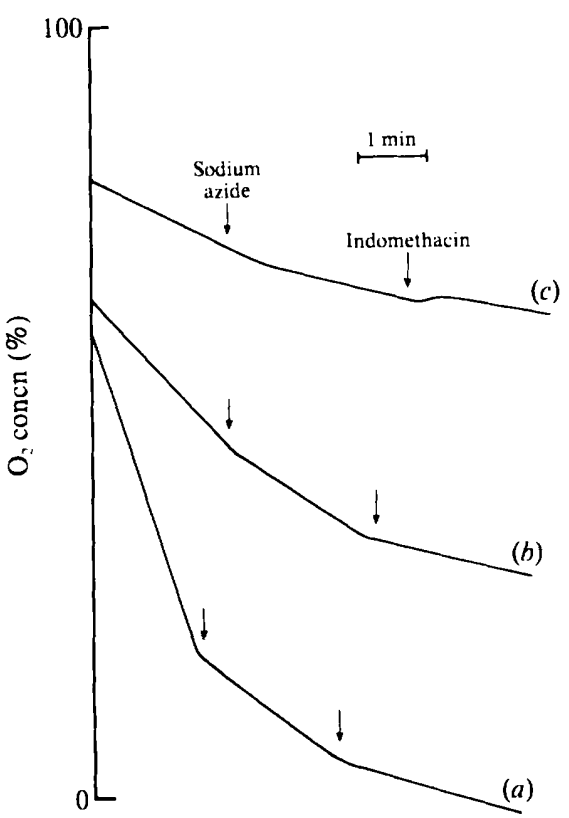

Fig. 1
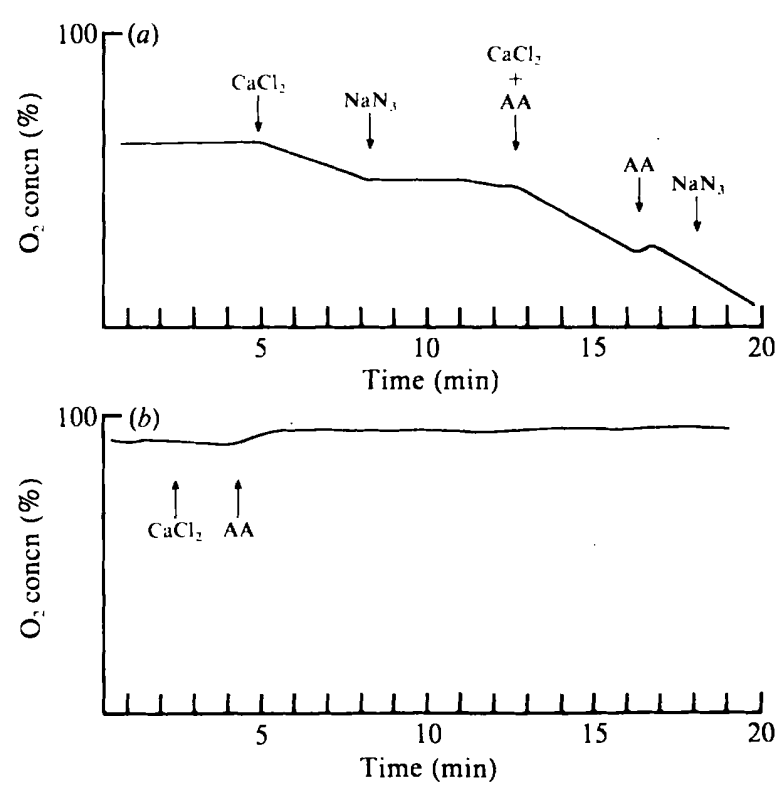

Fig. 2

Fig. 1. Effect of respiratory and eicosanoid inhibitors on the oxygen consumption of vegetative and developing cells of $D$. discoideum. Exponential phase cells were allowed to develop in phosphate buffer at $10^{7}$ cells $\mathrm{ml}^{-1}$ for $0(a), 3(b)$ and $10 \mathrm{~h}(c)$ and then $3 \mathrm{ml}$ of the cell suspension was placed in an electrode chamber. After the initial oxygen consumption rate was recorded, 6 mM-sodium azide and then $500 \mu \mathrm{M}$-indomethacin were added to the cells. The $100 \%$ value on the ordinate represents the oxygen concentration in air-saturated buffer. The oxygen consumption rates were calculated from the slopes of the appropriate tracings. Data shown are representative tracings of two independent experiments using the inhibitor concentrations shown above. Similar results were obtained with other concentrations of azide and various eicosanoid inhibitors in five additional experiments (data not shown).

Fig. 2. Effect of AA on oxygen consumption in cell lysates. (a) Vegetative cell lysates prepared by suspending $D$. discoideum cells in ice-cold homogenization buffer. A sample of the lysate was transferred to an oxygen electrode chamber maintained at $30^{\circ} \mathrm{C}$ and $6 \mathrm{~mm}-\mathrm{CaCl}_{2}$ and $3 \mathrm{~mm}$-sodium azide $\left(\mathrm{NaN}_{3}\right)$ were added sequentially. After the sodium azide, $6 \mathrm{mM}-\mathrm{CaCl}_{2}$ was added $30 \mathrm{~s}$ prior to $100 \mu \mathrm{M}$-AA. Further additions of $100 \mu \mathrm{M}$-AA and $3 \mathrm{~mm}$-sodium azide were made about 5 min later. (b) Oxygen electrode recording of the addition of $\mathrm{CaCl}_{2}(6 \mathrm{mM})$ and $\mathrm{AA}(100 \mu \mathrm{M})$ to lysis buffer in the absence of lysate. The tracing shown is representative of three independent sets of observations.

\section{Table 1. Oxygen consumption by developing D. discoideum cells}

Cells of different developmental ages were incubated in an oxygen chamber, and oxygen consumption was measured initially, and after sequential additions of $6 \mathrm{mM}$-sodium azide and $500 \mu \mathrm{M}$-indomethacin. Oxygen consumption rates were calculated from the slopes of the tracings during the appropriate incubation phases, and are expressed as $\mu 1 \mathrm{O}_{2} \mathrm{~min}^{-1}$ per $10^{7}$ cells. Values are the means of two independent experiments.

\begin{tabular}{cccc} 
Cell & \multicolumn{3}{c}{ Rate of oxygen consumption } \\
\cline { 2 - 4 } age (h) & Untreated & $\begin{array}{c}\text { Plus sodium } \\
\text { azide }\end{array}$ & $\begin{array}{c}\text { Plus } \\
\text { indomethacin }\end{array}$ \\
0 & 1.09 & 0.41 & 0.28 \\
3 & 0.48 & 0.33 & 0.12 \\
10 & 0.27 & $0 \cdot 13$ & 0.10
\end{tabular}


Table 2. Stimulation of oxygen consumption in post-mitochondrial supernatants by different PUFAs

Post-mitochondrial supernatants (prepared as described in Methods) were diluted to $8.0 \mathrm{mg}$ protein $\mathrm{ml}^{-1}$ and supplemented with $3 \mathrm{~mm}$-calcium. Each PUFA tested (dissolved in ethanol) was then added to a final concentration of $1.0 \mathrm{mM}$ and the resulting oxygen consumption measured. Data shown are the means of four independent observations for AA and two observations each for the other PUFAs.

PUFA

Arachidonic acid $(20: 4)$

Linoleic acid (18:2)

Linolenic acid (18:3)

Eicosatrienoic acid (20:3)

Eicosapentaenoic acid (20:5)

Lauric acid (12:0)
Rate of oxygen consumption $\left.\left[\mu \mathrm{mol} \mathrm{O}{ }_{2} \mathrm{~min}^{-1} \text { (mg protein }\right)^{-1}\right]$

0.20

0.48

0.23

0.54

0.27

0.0

Table 3. Effect of inhibitors on oxygen consumption in $D$. discoideum homogenates

\begin{abstract}
Oxygen consumption was measured in homogenates of vegetative or developing cells after addition of $\mathrm{AA}$ and various concentrations of inhibitor, as shown below. Oxygen consumption rates in the presence of inhibitors(s) are expressed relative to the AA-stimulated oxygen consumption rates for the corresponding uninhibited control; this was 0.20 and $0.29 \mu \mathrm{mol} \mathrm{min}^{-1}$ per $10^{7}$ cells, for vegetative and developing cells respectively. AA was added at $200 \mu \mathrm{M}$, and inhibitors were added as follows: sodium azide $\left(\mathrm{NaN}_{3}\right), 3 \mathrm{mM}$; SHAM, $3 \mathrm{~mm}$; ETYA, $10 \mu \mathrm{M}$; Mec, $10 \mu \mathrm{M}$. Acetone $(20 \mu \mathrm{l})$ and ethanol $(10 \mu \mathrm{l})$ were added as solvent controls for the SHAM and eicosanoid inhibitors respectively. Values are the means $\pm \mathrm{SE}$ of the number of observations given in parentheses.
\end{abstract}

Ratio (Rate of $\mathrm{O}_{2}$ consumption)

(Rate of AA-stimulated $\mathrm{O}_{2}$ consumption)

Addition(s)

AA

$\mathrm{AA}+\mathrm{NaN}_{3}$

$\mathrm{AA}+\mathrm{NaN}_{3}+\mathrm{SHAM}$

$\mathrm{AA}+\mathrm{NaN}_{3}+\mathrm{SHAM}+$ ETYA

$\mathrm{AA}+\mathrm{NaN}_{3}+\mathrm{SHAM}+\mathrm{Mec}$

$\mathrm{AA}+\mathrm{NaN}_{3}+$ Acetone + Ethanol

\begin{tabular}{ll}
\hline Vegetative cells & Developing cells \\
$1(2)$ & $1(5)$ \\
$0.95 \pm 0.06(2)$ & $0.88 \pm 0.04(5)$ \\
$0.98 \pm 0.07(2)$ & $0.95 \pm 0.18(2)$ \\
$0.62(1)$ & $0.16(1)$ \\
$0.75(1)$ & $0.50(1)$ \\
$1.10 \pm 0.10(2)$ & $0.95 \pm 0.09(2)$
\end{tabular}

\title{
AA-stimulated oxygen consumption in cell lysates
}

We next investigated the effect of AA and other polyunsaturated fatty acids (PUFAs) on oxygen consumption in cell lysates. Cell lysates were made in the presence of EGTA and then placed in the measuring chamber. Oxygen consumption was not detectable until calcium was added. This consumption was completely inhibited by the addition of $3 \mathrm{~mm}$-sodium azide and is believed to be mitochondrial since no calcium-stimulated oxygen consumption was seen in postmitochondrial supernatants. Addition of $6 \mathrm{mM}$-calcium, followed $30 \mathrm{~s}$ later by $100 \mu \mathrm{M}-\mathrm{AA}$, produced a dramatic stimulation of oxygen consumption. This stimulated level of oxygen consumption was slightly increased by a further addition of $100 \mu \mathrm{M}$-AA (Fig. 2) and reached a maximum at about $275 \mu \mathrm{M}$-AA (data not shown). Further additions of azide were without effect (Fig. 2). No spontaneous oxidation of AA was observed in the absence of cell extract (Fig. $2 b$ ). Similar levels of stimulation were seen with linoleic acid (18:2), linolenic acid $(18: 3)$, eicosatrienoic acid (20:3), and eicosapentaenoic acid (20:5). However, lauric acid (12:0) had no effect (Table 2).

\section{Effect of eicosanoid inhibitors on AA-stimulated oxygen consumption}

Post-mitochondrial supernatants from vegetative and developing cells were first stimulated with $200 \mu \mathrm{M}$-AA and the oxygen consumption measured. Respiration and eicosanoid synthesis inhibitors were then added sequentially and oxygen consumption determined after each 
(a)

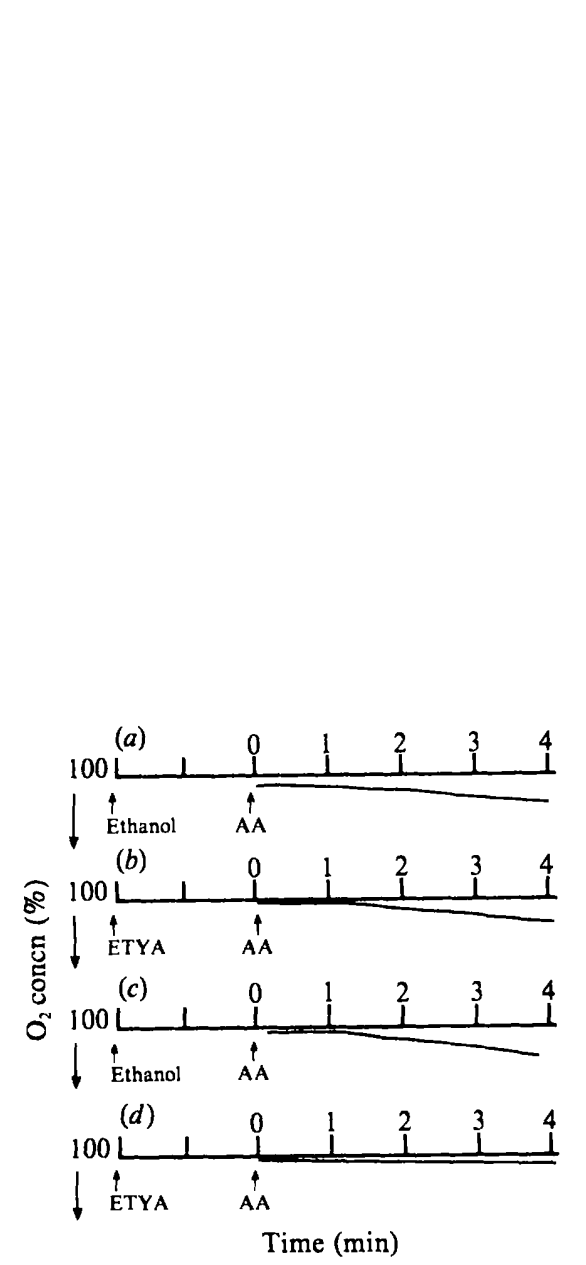

Fig. 3
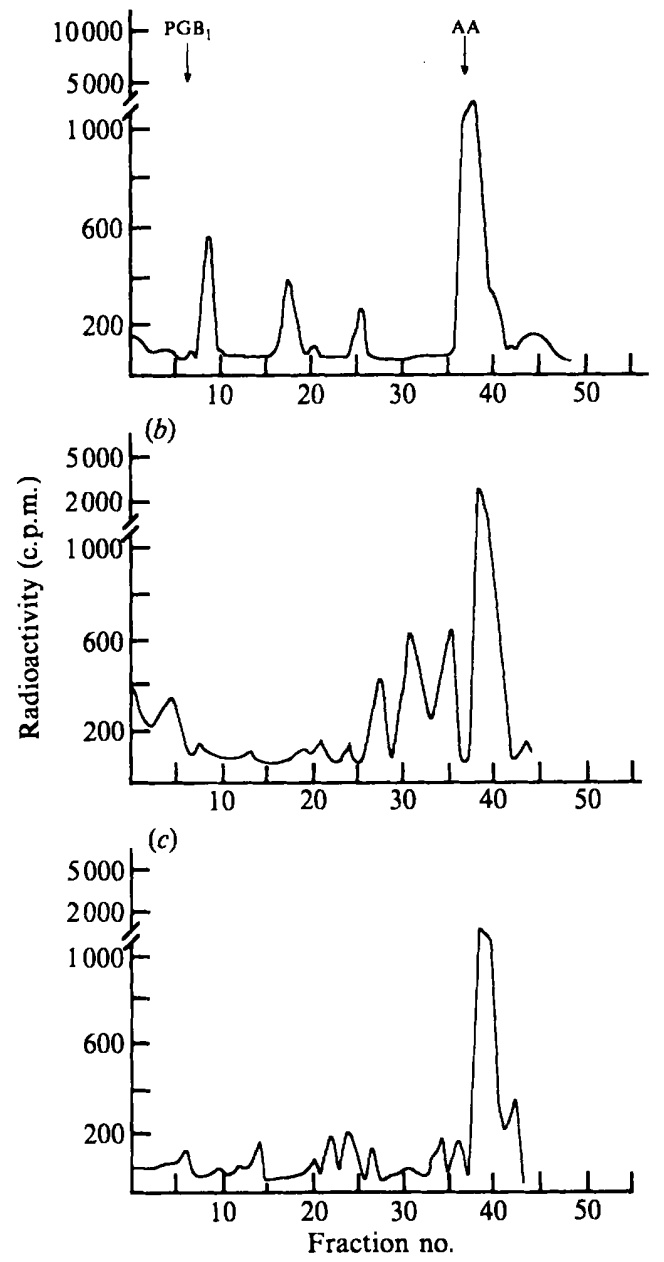

Fig. 4

Fig. 3. Effect of ETYA on AA-stimulated oxygen consumption in post-mitochondrial supernatants of $D$. discoideum prepared from vegetative $(a, b)$ and $6 \mathrm{~h}$-developed $(c, d)$ cells as described in Methods. These were preincubated for $2 \mathrm{~min}$ with ethanol $(a, c$; solvent control) or with $25 \mu \mathrm{M}$-ETYA $(b, d)$ then $200 \mu \mathrm{M}-\mathrm{AA}$ was added at time $=0 \mathrm{~min}$. Tracings shown are representative of two independent experimental runs.

Fig. 4. Metabolism of $\left[{ }^{14} \mathrm{C}\right] A A$ in post-mitochondrial supernatants of $D$. discoideum. Lysates from vegetative and developing cells were incubated with $\left[{ }^{14} \mathrm{C}\right] \mathrm{AA}$ for $15 \mathrm{~min}$ and $\mathrm{AA}$ and its metabolites were extracted and analysed by HPLC. (a) Vegetative lysate; (b) $6 \mathrm{~h}$ lysate; (c) 6 h lysate plus $50 \mu \mathrm{M}$ ETYA. The results shown are representative of two independent experiments.

addition. Results are expressed as oxygen consumption relative to the AA-stimulated, uninhibited control (Table 3). Neither azide nor salicylhydroxamic acid (SHAM), an alternative respiratory pathway inhibitor in certain plants and fungi (Schonbaum et al., 1971), and in $D$. discoideum (Woffendin \& Griffiths, 1984), had a significant effect on oxygen consumption in the supernatants from either vegetative or developing cells. However, the addition of the eicosanoid synthesis inhibitors ETYA or meclofenamate $(\mathrm{Mec}$, at $10 \mu \mathrm{M})$ reduced the oxygen consumption by $30 \%$ in vegetative cells and by $60 \%$ in developing cells. Consistent with this, we observed that addition of ETYA to the cell lysates prior to AA almost completely blocked the AA-stimulated oxygen consumption in developing cells, while in vegetative cells oxygen consumption was reduced by about $20 \%$ (Fig. 3 ). 
In an attempt to determine the oxygenation products(s) of AA produced by $D$. discoideum, cell lysates were incubated with $\left[{ }^{14} \mathrm{C}\right] \mathrm{AA}$ alone or in the presence of ETYA, the alkyne analogue of AA, which acts as a lipoxygenase/cyclooxygenase inhibitor, and the products were analysed by HPLC. The results show that a different set of labelled products is formed by lysates from vegetative (Fig. $4 a$ ) and developing (Fig. $4 b$ ) cells, and that the formation of these products is inhibited by ETYA (Fig. 4c). No AA metabolites were detected in the absence of calcium, or if boiled lysate was used. The nature of these AA-derived products has not been further investigated.

\section{DISCUSSION}

We have measured oxygen consumption by $D$. discoideum cells during growth and development, and investigated the contribution of eicosanoid metabolism to this process. The measurements reported here show that oxygen consumption by intact $D$. discoideum cells can be divided into an azide-sensitive (respiratory) and an azide-insensitive (non-respiratory) component. At least part of the azide-insensitive component can be inhibited by indomethacin at concentrations comparable to those used to inhibit cAMP accumulation (Sampson \& Town, 1985), developmental gene expression, and cell differentiation (Town et al., 1985). This indomethacin-sensitive component is larger in cells starved for $3 \mathrm{~h}$ than in either vegetative cells or in cells starved for $10 \mathrm{~h}$, and correlates in time with the appearance of the cAMP oscillatory system in developing cells.

In cell lysates, azide-insensitive oxygen consumption was stimulated by the addition of AA and other poly-unsaturated fatty acids. The concentration of AA required to produce maximum stimulation of oxygen consumption in $D$. discoideum is similar to that which gives maximal stimulation of protein kinase $C$ in human neutrophils (McPhail et al., 1984). It is difficult to relate these values to the in vivo levels of AA for two reasons. Firstly, most of the cellular AA occurs as phospholipid so that free AA levels rise only transiently during stimulation and have not been directly determined. In addition, the amount of AA present in $D$. discoideum cells grown in the absence of exogenous AA is too low to be detected (Weeks, 1976). The relative efficacy of the other PUFAs tested is only approximate, since concentration optima for each of these PUFAs was not determined. At least part of the AA-stimulated azide-insensitive oxygen consumption could be inhibited by ETYA and Mec, both known to be eicosanoid synthesis inhibitors in animal systems. AA-stimulated oxygen consumption was also inhibited by prior addition of ETYA. Finally, conditions which hlock AA-dependent oxygen consumption also prevent the conversion of radiolabelled $A A$ lo eicosanoid-like products.

The results presented here extend our previous ubservations suggesting a role for eicosanoids in $D$. discoideum development by providing direct evidence for an arachidonate-dependent oxygen consuming process. Oxidation of $\mathrm{AA}$ is a general property of both the cyclooxygenase and lipoxygenase enzymes. PGs are formed by the cyclooxygenase enzyme, which incorporates 2 mol oxygen into a polyunsaturated fitty i.sid. A lipoxygenase enzyme initiates a second pathway for AA metabolism to hydroxy......iatetraenoic acids and leucotriene by incorporation of one mol oxygen. Our results are inore suggestive of a lipoxygenase rather than a cyclooxygenase reaction because ETYA is a more potent inhibitor of the former activity. In addition, the radiolabelled ETYA-sensitive reaction products exhibit retention times between those of $\mathrm{PGB}_{1}$ and free $\mathrm{AA}$, which is the range expected for most hydroxyeicosatetraenoic acids, whereas most common $\mathrm{PGs}$ have retention times less than $\mathrm{PGB}_{1}$ in this chromatographic system (Eling et al., 1982). Further work will be required to characterize these reactions and their products, and to define their role in the $D$. discoideum life cycle.

This research was supported by grants from the National Science Foundation (PCM 8209762) and from the American Heart Association (North Fast Ohio Affiliate). We thank Dr George Perry for helpful advice and discussions. 


\section{REFERENCES}

Chung, W. K. \& Coe, E. L. (1978). Correlations among the responses of suspensions of Dictyostelium discoideum to pulses of $3^{\prime}, 5^{\prime}$-cyclic AMP. Biochimica et biophysica acta 544, 29-44.

DohrmanN, V., Fisher, P. R., BruderleiN, M., LuChNer, B. \& Williams, K. L. (1984). Arachidonic acid and related molecules affect the behaviour of Dictyostelium discoideum slugs. Journal of General Microbiology 130, 2685-2698.

Eling, T., Tainer, B., Ally, A. \& Warnock, R. (1982). Separation of arachidonic acid metabolites by high pressure liquid chromatography. Methods in Enzymology 86, 511-517.

J AKSCHIK, B. A., HARPER, T. \& MuRPHY, R. C. (1982). The 5-lipoxygenase and leukotriene forming enzymes. Methods in Enzymology 86, 30-37.

LoOMis, W. F. (1982). The Development of Dictyostelium discoideum. p. 235. New York: Academic Press.

McPhail, L. C., Clayton, C. C. \& Snyderman, R. (1984). A potential second messenger role for unsaturated fatty acids: activation of $\mathrm{Ca}^{2+}$-dependent protein kinase. Science 224, 622-625.

Newell, P. C., Europe-Finner, G. N. \& Small, N. V. (1987). Signal transduction during amoebal chemotaxis of Dictyostelium discoideum. Microbiological Sciences 4, 5-11.

SAMPson, J. \& Town, C. D. (1985). Suppression of cyclic AMP induced cell excitation in Dictyostelium discoideum by inhibitors of eicosanoid oxidation. FEMS Microbiology Letters 27, 209-213.

Schonbaum, G. R., Bonner, W. D., JR, Storey, B. T. \& BaHR, J. T. (1971). Specific inhibition of the cyanide-insensitive respiratory pathway in plant mitochondria by hydroxamic acids. Plant Physiology 47, 124-128.

Town, C. D., Krill, D. \& Hassid, A. I. (1985). Inhibition of differentiation in Dictyostellium discoideum by anti-inflammatory drugs. Development, Growth and Differentiation 27, 111-116.

Umbreit, W. W., Burns, R. H. \& Stauffer, J. F. (1972). Manometric Biochemical Techniques. p. 7. Minneapolis, Minn.: Burgess Publishing Co.

WATTS, D. J. \& AshworTh, J. M. (1970) Growth of myxamoebae of the cellular slime mold Dictyostelium discoideum in axenic culture. Biochemical Journal 119, 171-174.

WEEKS, G. (1976). The manipulation of the fatty acid composition of Dictyostelium discoideum and its effect on cell differentiation. Biochimica et biophysica acta 450, 21-32.

Woffendin, C. \& Griffiths, A. J. (1984). The effect of respiratory inhibitors during growth and development of Dictyostelium discoideum. Biochimica et biophysica acta 766, 542-548. 